\title{
Türk Dünyasında Kültür ve Yaratıcı Endüstri Yönetişimi Üzerine Bir Değerlendirme*
}

\section{Serhat Kaymas ${ }^{* *}$}

\section{$0 \ddot{z}$}

Bu çalışma; ülkelerin yeni refah ve istihdam kaynakları olarak dikkat çeken kültür ve yaratıcı endüstrileri, gelişmekte olan ülkeler perspektifinden ele almayı amaçlamıştır. Çalışma; kültür ve yaratıcı endüstrileri, kamu politikaları ve yönetişim modelleri arayışı ile gerçekleştirilen bir tartışma ile değerlendirmektedir. $\mathrm{Bu}$ doğrultuda; söz konusu endüstrilerin gelişmekte olan ülkeler için yeni bir "firsatlar" alanını mı yoksa yirmi birinci yüzyılın şafağında, emperyalizmin yeni biçimlerini mi oluşturduğu Türk Dünyası özelinde değerlendirilmektedir. Çalışma; kamu politikaları analizi üzerinden, Türk Dünyası için bu alanda öneriler geliştirmiş̧ir. Türk Dünyasının kültür ve yaratıcı endüstrileri yönetişimi için, örnekleri gelişmiş ülke deneyimlerinde gözlenen uluslarasılaşma modelinin sınanmasına yönelen çalışma, Türk Dünyasında kültür ve yaratıcı endüstrilerin yönetişimi için, gelişmekte olan ülkeler özelinde yönetişim modellerini ele almıştır. Çalışma, Türk Dünyasında kültür ve yaratıcı endüstrilerin uluslararasılaşması temelinde öneriler geliştirmiştir.

\section{Anahtar Kelimeler}

Kültür endüstrileri, yaratıcı endüstriler, internet erişimi, sayısal eşitsizlik, bilgi toplumu, kültür ve yaratıcı endüstrilerin yönetişimi.

\footnotetext{
Geliș Tarihi: 14 Şubat 2018 - Kabul Tarihi: 17 Nisan 2018 Bu makaleyi şu şekilde kaynak gösterebilirsiniz: Kaymas, Serhat (2019). “Türk Dünyasında Kültür ve Yaratıcı Endüstri Yönetişimi Üzerine Bir Değerlendirme”. bilig - Türk Dünyast Sosyal Bilimler Dergisi 90: 215-243.

** Doç. Dr., Hacettepe Üniversitesi, İletişim Fakültesi, İletişim Bilimleri Bölümü - Ankara/Türkiye ORCID ID: https://orcid.org/0000-0003-4096-1546 ahmetserhat.kaymas@windowslive.com
} 


\section{Giriş}

Neo liberal politikalar eliyle inşa edilen "küreselleşme", "bilgi toplumu" ve bilgi temelli toplumsal dönüşüm tartışmalarının üzerinden geçen yirmi yılın ardından; bir "değerler dizisi” değişimini de içerecek denli yeni bir politika ve uygulama alanı olarak gelişen "yaratıcı ve kültür endüstrileri”, bu çalışmada gelişmekte olan ülkeler perspektifi içerisinde ele alınacaktır. Çalışmada; gelişmekte olan ülkelerin kültür ve yaratıcı endüstrileri yönetişimi ilişkisi, Türkiye ve Türk Cumhuriyetleri özelinde, ele alınmakta ve alternatif bir yönetişim modelinin geliştirilmesi için çaba gösterilmektedir.

Kültür ve yaratıcı endüstriler; ülkeler için istihdamın ve refahın yeni kaynakları olarak 1990'lı yıllardan itibaren, Avusturalya ve İngiltere öncelikli olmak üzere, gelişmiş ülkelerin politika ve uygulamalarını biçimlendiren yeni kaynaklar olarak gelişirken, gelişmekte olan ülkeler için de önemli bir tartışma uzamı oluşturur. Gerçekten de; gelişmekte olan ülkelerin küresel kültürel akış içerisinde nasıl yer edinebileceği? Neo liberal politikalar eliyle inşa edilen ve çoğu tek başına Amerika Birleşik Devletleri merkezli sınırlı sayıdaki bir dizi çok uluslu şirketin küresel egemenliğini pekiştiren küreselleşme sürecinin, bu kez kültür ve yaratıcı endüstriler eliyle birlikte geri mi döndüğü? Bilgi toplumu mirasının, insani yaratıcılığın, yeteneğin ve fikri hakların kullanılmasıyla yeniden metalaştırdığı dönemin bu kez kültür ve yaratıcı endüstriler deneyimi ile birlikte sermayenin hegemonyasını yeniden pekiştiren bir dönemin mi başladığı? Gelişmekte olan ülkelerin, gelişmiş ülkelere olan bağımlığının kültür politikalarına yeniden dönerek nasıl aşılabileceği? Yukarıda sözü edilen tartışma alanlarının yalnızca bir kısmını oluşturmaktadır. Bununla birlikte, "gelişmekte olan ülkeler” söyleminin, kültür ve yaratıcı endüstriler içerisindeki anlamının, en azından, genel bir fikir verebilmesi için tartışılması gerekmektedir.

\section{Çalışmanın Yöntemi}

Gelişmekte olan ülkeler söylemi, sosyal bilimler içerisinde yaygın olarak kullanılmasına rağmen, ülkelerin "gelişmiş" ve "gelişmekte olan” söylemini belirleyebilecek ölçütlerin nasıl seçilebileceği, halen yaygın bir tartışmanın odağında yer almaktadır. Gelişmiş ya da gelişmekte olan ülkelerin belirlenebilmesi ve aralarında anlamlı bir ayrımın geliştirilebilmesi adına kullanılan "İnsani Gelişme Endeksi” (Human Development In- 
dex-HDI) yukarıdaki belirleme için önemli bir örneği oluşturmaktadır. Ancak, ülkelerin gelişmişlik düzeyini belirlemeye yönelen sözü edilen Endekslerin, ülkelerin gelişmişlik düzeyini ağırlıklı olarak ekonomik gelişmişlik üzerinden değerlendirilmesinin yetersiz olduğu, en azından bu çalışmanın yazarı tarafından, düşünülmektedir. Gerçekten de, ülkelerin gelişmişlik düzeyinin yalnızca ekonomik olarak değil diğer temel alanlarda da değerlendirilmesi gerekliliği açıtıtr. Örneğin, toplumsal cinsiyetler arasındaki eşitlik, toplumun sağlık hizmetlerine erişiminin yaygınlığı, eğitim olanaklarının geliştirilmesi, ülkelerin demokrasiye bağlığının değerlendirilmesi ile özellikle bilgi toplumu tartışmaları dikkate alındığında, toplumun geniş kesimlerinin internet ile yeni enformasyon teknolojilerine erişimi ile kaynakların kullanımındaki eşitliğin sağlanması ülkelerin gelişmişlik düzeylerinin belirlenmesinde anlamlı bir önceliğe ve öneme sahiptir. Bununla birlikte, İnsani Gelişmişlik Endekslerinin farklı bir açıdan daha eleştirilmesi gerekir. Gerçekten de; eğer ekonomik refah olanaklarının artışı, ülkelerin gelişmişliğini belirleyen neredeyse tek kaynağı oluşturmaktaysa, gelişmekte olan ülkelerin ekonomik büyüme hızlarında gelişmiş ülkeleri geçmesi durumunda bu "genişlemenin" nasıl yorumlanabileceği tartışmalıdır.

Kültür ve yaratıcı endüstriler özelinde ise "gelişmişlik" düzeyinin nasıl değerlendirilebileceği, ekonomik verilerin ötesine geçen değerlendirmelere ihtiyaç duymaktadır.

Birleşmiş Milletler Ticaret ve Kalkınma Konseyi (2010: 24) tarafından geliştirilen "gelişmekte olan ülkeler söylemi" anlamlı bir yanıt tam da bu bağlamda görünür kılmaktadır. Konseyin tanımı içerisinde gelişmekte olan ülkeler, "yaratıcı endüstrileri için yatırımcı eksikliği yaşayan, girişimci yeteneklerinin yetersiz olduğu, destekleyici finansman mekanizmasını oluşturamamış, kurumsallaştırma süreçleri ve yaratıcı endüstrilerinin geliştirilmesini teşvik eden yasal çerçevelerinin geliştirilmemiş" olduğu ülkeleri işaret etmektedir. Bu yönüyle tanım, ilk okuyuşta gelişmekte olan ülkeler olarak değerlendirilen ülkelere dair "keskin" bir eleştiri olarak görülebilir ise de gerçekte sözü edilen ülkelerin, bu alanda karşılaştıkları sorunlarını işaret etmektedir. (http://www.unctadstat.unctad.org, 2018: 1). BM Ticaret ve Kalkınma Konseyi Raporlarında, Kuzey Kıbrıs Türk Cumhuriyeti 
yer almamakla birlikte, Türk Cumhuriyetleri "geçiş sürecindeki ülkeler" olarak değerlendirilmektedir. Türkiye ise, Birleşmiş Milletler Ticaret ve Kalkınma Konseyi'nin "Yaratıcı Ekonomi Görünüşü ve Ülke Profilleri Raporu’nda” (http://www.unctad.org, 2015: 9), dünyanın en çok kültür ve yaratıcı endüstrilerine ait mal veya hizmetleri ihracatı gerçekleştiren ülkeleri arasında yer almışır. Türkiye, Malezya, Meksika, Çin Halk Cumhuriyetleri, Arjantin ve Güney Kore ile birlikte en çok kültür ve yaratıcı endüstri mal veya hizmeti ihraç eden ülkeleri arasında yer almaktadır.

Türkiye ve Türk Cumhuriyetleri'nin kültür ve yaratıcı endüstrileri alanında küresel kültürel akış içerisinde yeniden düşünülebilmesi adına oldukça önemli bir cesaret vermektedir. Bu çalışma içerisinde, bu alt bölümün henüz girişinde yer alan sorular üzerinden kültür ve yaratıcı endüstrilerin bir gelişmişliğe dair bir değerler dizisi içerisinde ele alınması tam da böylesi bir cesaret ile anlam bulmaktadır. Hartley, Potts, Cunningham, Flew, Keane ve Banks'ın (2013: 106); küreselleşme ve yaratıcı endüstriler arasında birbirine paralel bir ilişki olmasına rağmen, bir yandan da böylesi bir endüstrinin neo liberal karaktere sahip olan küreselleşme sürecini gerilettiğini belirtir. Fikri Zul Fahmi, Philip McCann ve Sierdjan Koster (2017: 1368) ise, kültür ve yaratıcı endüstrilerin yönetişimi adına gelişmiş ve gelişmekte olan ülkeler arasındaki farklılıkları değerlendirir. Bu doğrultuda, gelişmiş ve gelişmekte olan ülkeler arasındaki temel farklılıklar araştırmacılara göre şu şekilde maddeleştirilir: (1) Yaratıcı ekonomi politikalarının benimsenmesi ve uygulanması arasındaki "motivasyon" farlılıklarının belirgin bir biçimde dikkat çekmesi bu doğrultudaki ilk farklılıktır. Fahmi ve çalışma arkadaşlarının belirlediği üzere; Kuzey Amerika, Avustralya ve Avrupa'da, kültür ve yaratıcı endüstri politikaları yaratıcı ekonomi üzerinden bir bütün olarak ekonomilerinin yeni kazanımlar elde etmesine ve gelişmiş bölgeleri kadar ihmal edilmiş, sanayisini geliştirememiş, bölgelerinde yeni kalkınma stratejilerinin oluşturulmasına yönelmiştir. Gelişmekte olan ülkeler de ise böylesi bir kalkınmanın aksine, yaratıcı ve kültür endüstrileri politikalarının kültürel metaların üretim harcamalarının düşürülmesi doğrultusunda tam da söz konusu ülkelerin, göreli “avantajlarını” öne çıkartmaya yönelik bir çaba göstermektedir. (2) Gelişmiş ülkelerin bölgesel ekonomilerinin gelişememiş olması bir diğer sorun alanını oluşturmaktadır. Kültür ve yaratıcı endüstrilerin ihtiyaç duyduğu 
teknolojik alt yapı eksikliği, yaratıcıllı̆ın ve entelektüel kapasitenin gelişmesinin engellenmesi ile sonuçlanmaktadır. Gelişmekte olan ülkelerin, kültür ve yaratıcı endüstri yönetişimi boyunca ortaya çıkan bir diğer sorun alanı ise (3) yaratıcı ve kültür endüstrilerinin gelişmesi için hayati bir öneme sahip olan fikri mülkiyet haklarının gelişmemiş olmasıdır. Fikri mülkiyet ve telif haklarının korunmasına önem verilmemesi, hatta fikri mülkiyet hakkı kavramına dair bir farkındalığın dahi geliştirilmemiş olması, gelişmekte olan ülkelerin kültür ve yaratıcı endüstri politikalarının gelişimi üzerindeki başlıca engelleri oluşturmaktadır. Bu olumsuz görünüme rağmen, gelişmekte olan ülkelerin, bir dizi önemli olanağa sahip oldukları da belirtilmelidir . Bununla birlikte, gelişmekte olan ülkelerin, yakın kültürel alanlarda yer alan diğer ülkelerle ve çeşitli nedenlerle küresel olarak yaygınlık gösteren nüfuslarına yönelik sürdürülebilir bir politikanın aracı olarak kültür ve yaratıcı endüstrilerinin uluslararasılaşması yerine, gelişmiş ülkelerden politika transferine yönelmeleri ise başlı başına önemli bir sorun olarak dikkat çekmektedir. Fikri Zul Fahmi, Philip McCann ve Sierdjan Koster'in (2017: 1372-1374) değerlendirdiği üzere, politika transferinin bir politika modeli olarak gelişmekte olan ülkelerde kurumsallaşması başlangıcından itibaren bir dizi önemli sorunla çerçevelenmiştir. Bu doğrultuda; (a) bu süreçte kimin yer aldığı (b) neyin transfer edildiği ve (c) düşüncelerin nasıl transfer edilebileceği olmak üzere bir dizi önemli açıdan tartışılması gereken sonuçlara yol açmaktadır.

Gelişmekte olan ülkelerin böylesi bir politika transferi yerine, özellikle kültür ve yaratıcı endüstrilerin yönetişimi için ihtiyaçları temelinde belirlenen yeni bir politikaya, kültür ve yaratıcı endüstrilerin uluslararasılaşması politikasına, dönmesinin anlamlı olduğu belirtilmelidir. Tomas Mitkus'un (2016: 31-32) değerlendirdiği üzere; gelişmekte olan ülkelerde kültür ve yaratıcı endüstrilerin karşılaştı̆̆ iki önemli sorun ile "başa çıkılabilmesi" için kültür ve yaratıcı endüstrilerin söz konusu ülkelerdeki uluslararasılaşması politikasını yeniden düşünmenin bu doğrultuda anlamlı olduğu söylenmelidir. Mitkus (2016: 32), gelişmekte olan ülkelerin kültür ve yaratıcı endüstri projelerinin ancak uluslararası ölçekte desteklenmesiyle küresel kültürel akış içerisinde yer alabileceğini belirtir. Gelişmekte olan ülkelerin, kültür ve yaratıcı endüstrilerini uluslararasılaştırması girişimleri, gelişmekte olan ülkelerin sağladığı, ya da taahhüt ettiği, vergi olanak- 
ları ya da üretim maliyetlerinin düşürülmesi gibi imkânların sağlanması karşılığında gerçekleşirken gelişmekte olan ülkelerin, küresel kültürel akış içerisinde yer alabilmesi gittikçe güç bir sorun haline dönüşmektedir. Bununla birlikte, öncelikli olarak kültür ve yaratıcı endüstrilerin nasıl bir ekosisteme işaret ettikleri öncelikli olarak ele alınarak, tartışmanın Türk Dünyasına doğru genişletilmesi anlamlı olacaktır.

\section{Kültür ve Yaratıcı Endüstrilerin Kısa Tarihçesi}

Kültür ve yaratıcı endüstriler, refah ve istihdamın yeni kaynakları olarak, 1990 'lı yılların son döneminden itibaren öncelikle gelişmiş ülkelerin ardından küresel düzeyde de gittikçe genişleyen bir ilginin odağında yer almasına rağmen; "yaratıcı endüstri” kavramının, öngörüldügünün aksine, yeni olmadığı söylenmelidir. John Hartley (2005'den aktaran Hocaoğlu 2015: 190), "yaratıcı endüstri” kavramının ilk olarak on sekizinci yüzyılın "yaratıcı sanatlar" ve "kültürel endüstriler" fikirlerinin birbirine dönüştürülmesi ve böylesi bir dönüşüm içerisine tüketici ve vatandaş terimlerinin eklenmesi ile ortaya çıktığını belirtir. Kültür ve yaratıcı endüstrilerin, en azından ilk değerlendirme aşamasında, "eklektik" bir doğasının olduğu söylenebilir ise de gerçekte kavram ve bileşen alanların kendi içerisinde bir uyum oluşturduğu dikkate alınmalıdır. Bir diğer unsur ise; kültür ve yaratıcı endüstriler kavramı içerisinde kullanılan "kültür endüstrileri" teriminin, siyasa eliyle politika alanına dönüşüdür. Bununla birlikte, kitlesel eğlence anlayışı doğrultusunda eleştirildiği 1940'lı yılların ardından üzerinden geçen nerede ise yarım asrın ardından yaratıcı ve kültür endüstrileri politikaları içerisinde yeniden yer edinmesine rağmen, her iki kavramın farklı öznellikleri ve farklı üretim güçleri ile ilişkileri evrenini temsil etmesidir. Angela McRobie’nin (2016: 10-11) değerlendirdiği üzere, 1940 'lı yıllar boyunca kitlesel eğlence ve kitlesel üretim aracı olarak Frankfurt Okulu teorisyenlerinin kültür endüstrisi eleştirisi ilk eleştiri dizgesini oluşturur. Bu dönemin ardından 1980'li yıllar ve devamında Birmingham Çağdaş Kültürel Çalışmalar Merkezi'nin niteliksiz bir eğlencenin yayılışı ile daha önemlisi popüler kültür eliyle yok edilen sınıf mücadelesinin aracı olarak kültür endüstrilerini eleştirilerinin odağında aldıkları görülür. Ancak, eleştirilerin aslında Fordist üretim ilişkilerinin bu kez kültürel alan 
içerisinde yeniden üretilmesi olarak görülen bir kültür endüstrisi üzerine yapıldığ 1 belirtilmelidir. Kültür endüstrileri eliyle Fordizmin kültürel alandaki inşası, son kertesinde "kitlelerin aldatılışı olarak kültür endüstrileri” (Raunig 2013: 1-4) değerlendirmesine yol açmıştır. Bununla birlikte, Fordist dönemin kültürel simgesi olarak kültür endüstrileri anlayışının, yeni enformasyon ve iletişim teknolojilerinin üretim ilişkileri içerisinde genişleyen konumu ile simgelenen Post - Fordist, sanayi sonrası, toplum biçimlerinin kültürel simgesi olarak "kültür ve yaratıcı endüstriler" ile radikal bir ayrışma içerisinde olduğu belirtilmelidir.

Kültür ve yaratıcı endüstrilere dair çağdaş söylemler, kitlelerin aldatılması olarak kültür endüstrileri düşüncesini terk etmiş ve kültürel mal ve hizmet üreten sektörler olarak tanımlamıştır. Örneğin, Dal Yong Jin (2015: 56) kültür ve yaratıcı endüstrilerinin, ülkelerin yeni refah ve istihdam kaynakları olarak ekonominin diğer sektörleri kadar önemli olduğunu ve böylesi bir bileşkenin, yeni enformasyon ve iletişim teknolojilerinin kültürün gelişimindeki öncü rolü ile ilişkili olduğunu belirtir. Bu açıdan bakıldığında Post Fordist üretim yapısının ve ilişkilerinin bağlamını oluşturduğu kültür ve yaratıcı endüstrilerin; Terry Flew ve Stuart Cunningham'ın (2010: 116117) işaret ettiği üzere; geniş bir alana yayılırken, kültür ve yaratıcıllığ bu kez insani sermaye ile birleştirerek bir dizi alandaki değişimin öncülügünü oluşturdukları söylenmelidir. O denli ki, ülkelerin kültür politikaları alanına yeniden dönmesi bir yana, enformasyon toplumu ve enformasyon toplumuna dönüşüm politikalarının bu kez, "yaratıcı ekonomi” söylemi ile bütünleşerek kültür ve yaratıcı endüstriler içerisinde yeniden kurulması, yukarıda sözü edilen farklı bir “öznelliğin” sınırlarını oluşturmaktadır.

Kültür ve yaratıcı endüstrilerin hem "eklektik" yapısı ve hem de geniş bir alana yayılması öte yandan bu endüstrilere refah ve istihdamın yeni kaynakları olarak ülkeler ve ulus üstü düzenleyici örgütler tarafından gösterilen ilgi, kültür ve yaratıcı endüstrilerin tek bir tanımın paydası altında değerlendirilmesini engellemektedir. Bu açıdan, aşağıdaki Tablo 1 içerisinde gerek ülkeler ve ulusal düzenleyici otoriteler ve gerekse ulus üstü örgütler tarafından yapılan kültür ve yaratıcı endüstri tanımlarının bir bütünlük içerisinde yansıtılması anlamlı olacaktır. 
Tablo 1. Ulusal ve Ulus Üstü Düzenleyici Örgütler İ̧̧erisinde Kültür ve Yaratıcı Endüstri Tanımları

\begin{tabular}{|c|c|c|}
\hline \multicolumn{2}{|c|}{$\begin{array}{l}\text { Külttür ve Yaratıcı Endüstri } \\
\text { Tanımı Yapan Kurum }\end{array}$} & \multirow{2}{*}{$\begin{array}{l}\text { Kültür ve Yaratıcı Endüstri Tanımı } \\
\text { Bireysel yetenekler ve yaratıcılık teme- } \\
\text { linde, fikri mülkiyet haklarının kulla- } \\
\text { nılması ve geliştirilmesiyle istihdam ve } \\
\text { refah yaratan endüstrilerdir. }\end{array}$} \\
\hline & $\begin{array}{l}\text { İngiliz Kültür, } \\
\text { Medya ve Spor } \\
\text { Genel Müdürlüğ̈u } \\
\text { (DCMS 2001: 9) }\end{array}$ & \\
\hline & $\begin{array}{l}\text { Birleşmiş Milletler } \\
\text { Ticaret, Kalkınma } \\
\text { ve Gelişim Kongresi } \\
\text { (UNCTAD 2008: 4) }\end{array}$ & $\begin{array}{l}\text { Yaratıcı endüstriler, yaratıcılık ve ente- } \\
\text { lektüel sermayenin temel girdi olarak } \\
\text { kullanıldığı mal ve hizmetlerin yaratıl- } \\
\text { dığı, üretildiği ve dağıtıldığı sektörleri } \\
\text { oluşturur. }\end{array}$ \\
\hline $\begin{array}{l}\text { United Nations } \\
\text { Educational, Scientific and } \\
\text { Cultural Organization }\end{array}$ & $\begin{array}{l}\text { Birleşmiş Milletler } \\
\text { Eğitim, Bilim ve } \\
\text { Kültür Örgütü } \\
\quad(2018: 1)\end{array}$ & $\begin{array}{l}\text { Kültürel sanatsal veya kültürel mirasla } \\
\text { bağlantılı bir doğaya sahip olan ürün, } \\
\text { hizmet veya eylemlerin üretimini, } \\
\text { ilerletilmesini, dağıtılmasını ve / veya } \\
\text { ticarileştirilmesini birincil amacı olarak } \\
\text { belirleyen eylemlerin gerçekleştirildiği } \\
\text { sektörlerdir. }\end{array}$ \\
\hline Whe & $\begin{array}{l}\text { Dünya Fikri Haklar } \\
\text { Örgütü }(2018: 1)\end{array}$ & $\begin{array}{c}\text { Telif veya telif hakları ile ilgili hakların } \\
\text { kullanıldığı endüstriler genellikle telif } \\
\text { hakları temelli ya da yaratıcı endüstriler } \\
\text { olarak isimlendirirler. }\end{array}$ \\
\hline 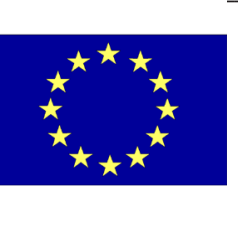 & $\begin{array}{l}\text { Avrupa Konseyi } \\
\quad(2012: 2)\end{array}$ & $\begin{array}{c}\text { Yaratıcı endüstriler, yaratıcı mal ve } \\
\text { hizmetlerin yaratımı, üretimi ve / veya } \\
\text { dağıtımı ve bunlar gibi yaratıcı unsurla- } \\
\text { rın daha geniş bağlamda ve diğer sektör- } \\
\text { lerle bütünleşmesi ile ilgili eylemlerden } \\
\text { oluşur. }\end{array}$ \\
\hline
\end{tabular}

Yukarıda Tablo 1 içerisinde, ulusal ve ulus üstü örgütler eliyle geliştirilen bir dizi yaratıcı endüstri tanımının, farklılıklar içeren yönlerine rağmen ortak olarak vurgulanan yönlerinin de olduğu söylenmelidir. Gerçekten de, kültürel ve yaratıcı endüstriler (1) bilgi toplumu kavrayışının yeniden keşfedilmesiyle ilgili olarak bilgi temelli yeni bir ekonominin, yaratıcı ekonomi, bu doğrultuda da yeni istihdam alanlarının oluşturulduğu sektörler olarak tanımlanmaktadır. (2) Bu doğrultuda yaratıcı endüstriler; bilgi toplumu mirasını, bireysel yetenek, yaratıcılık ve fikri hakların kullanılması ve geliştirilmesi ile insani sermaye ile birleştirerek yeni bir dizi alanla ilişkilendirirken aslında daha önce de belirtildiği üzere oldukça geniş ancak 
belirginlikten uzak bir sektör bileşkesini işaret etmektedir. (3) Tanımlar içerisindeki bir diğer önemli unsur ise; yaratıcı endüstrilerin özellikle gelişmekte olan ülkelerde sürdürülebilir bir kalkınma politikasının odağında yer almasıdır. Bununla birlikte, kültür ve yaratıcı endüstriler içerisinde "kültürü” vurgulayan iki tanımın Birleşmiş Milletler Ticaret ve Kalkınma Konseyi (UNCTAD) ile yine Birleşmiş Milletler Eğitim, Bilim ve Kültür (UNESCO) Örgütü tarafından gerçekleştirildiği görülür. Yaratıcı endüstrilerin bir ekonomi politikası içerisinde mi yoksa bir kültür politikası içerisinde mi ele alınması gerektiği henüz gelişmekte olan bir alan olarak kültür ve yaratıcı endüstrilerin nasıl bir yönetişim modeline sahip olması gerekliliği kamu politikaları gündemindeki önemli bir tartışma alanı olarak yer edinir. Gillian Doyle (2016:39); kültür ve yaratıcı endüstrilerin yönetişim modellerinde sosyo ekonomik boyutlar ile ekonomik boyutların eş zamanlı olarak var olması gerektiğini belirtir. Bununla birlikte; Fikri Zul Fahmi, Philip McCann ve Sierdjan Koster (2017: 1369-1370); gelişmekte olan ülkelerin kültür ve yaratıcı endüstrilerinin yönetişim modellerinde iki ana eğilimden birisinin ağırlık kazandığını ifade eder. Kültür ve yaratıC1 endüstrileri, kamu politikaları içerisinde ele almanın ilk yolu; kültürel politikalar ve kültürel ekonomi üzerine özel bir vurgu geliştirir. Böylesi bir vurgu içerisinde ülkelerin, kültür politikalarına yeniden dönmesi ya da Fahmi ve çalışma arkadaşlarının ifade ettiği üzere "ekonomilerin kültüre dönmesi” teşvik edilirken, kültürel metalar ekonomik değerinden bağımsız olarak ele alınır. Kamu politikaları içerisinde kültür ve yaratıcı endüstrileri değerlendirmenin ikinci yöntemi ise, ilk görüşün aksine bu kez "kültürün ekonomik bir değere sahip olmasını" amaçlar. Bu doğrultuda, Fahmi ve arkadaşlarının belirlediği üzere böylesi bir yaklaşımın temel sorusu; "insanların, fikirleri aracılığı ile nasıl refah sahibi olabileceği” üzerine yoğunlaşır. Ancak böylesi bir soru, kültür ve yaratıcı endüstrilerin geniş bir alana yayılırken, yönetişim tartışmaları içerisinde öncelikli olacak alanın "kültür mü?" ve "ekonomi mi? " soruları üzerinden ikileme yol açmaktadır. Bununla birlikte, gelişmekte olan ülkelerde söz konusu ikilemin, hem sürdürülebilir kalkınmanın aracı olarak hem de kültürel mirasın korunabilmesi ve geliştirilebilmesi adına, kendi içerisinde bir bütünlük oluşturması gerektiği açıktır. Ancak, özellikle gelişmiş ülkelerde bir kamu politikası aracı olarak geliştirilen kültür ve yaratıcı endüstriler politikalarının, gelişmekte 
olan ülkeler için tek boyutlu bir politika önerisi geliştirmesi ve böylesi bir “öneri” doğrultusunda gelişmekte olan ülkeleri yönlendirmesi en azından bir egemenlik ilişkisi içerisinde düşünüldüğünde anlaşılması güç bir durum olarak değerlendirilmemesi gerekir. O denli ki, gelişmiş ülkelerden gelişmekte olan ülkelere doğru tek boyutlu olarak gerçekleşen "politika transferlerinin” bir kamu politikası olarak üzeri örtülü amaçlarının değerlendirilmesi dahi böylesi bir tek boyutluluğu ortaya çıkartmaktadır. Bununla birlikte, daha önceki kısımlar içerisinde belirtildiği üzere kültür ve yaratıcı endüstrilerin oldukça geniş bir alana yayılmış olması aslında gelişmekte olan ülkelerin, kamu politikası olanaklarını da açık bir biçimde görünür kılmaktadır.

\section{Kültür ve Yaratıcı Endüstrilerin Sınıflandırılması ve Küresel Mali Büyüklüğüi}

Gelişmekte olan ülkeler ve kamu politikaları söz konusu olduğunda, kültür ve yaratıcı endüstrilerin nasıl bir yönetişim modeline sahip olması gerektiği yönündeki soru daha da önem taşımaktadır. Bu doğrultuda da, söz konusu endüstrilerin nasıl sınıflandırılabileceği önemli bir diğer tartışma gündemini oluşturmaktadır. Kültür ve yaratıcı endüstrilerin hem oldukça geniş bir alanda değerlendirilmesi hem de böylesi bir genişliğin aslında birbiriyle ilişkili olsa da eklektik bir niteliğinin olması, kültür ve yaratıcı endüstrilerin de geniş bir bağlam içerisinde sınıflandırılmasına yol açmıştır. Gelişmekte olan ülkelerin, kültür ve yaratıcı endüstrilerin bir dizi alanında ev sahipliği yapmasının ötesinde, kültürel mirasın söz konusu endüstriler içerisindeki konumu düşünüldüğünde, bizatihi bu endüstrilerin merkezini oluşturmaları sözü edilen geniş bağlamın içeriğini oluşturmaktadır. Tablo 2'de kültür ve yaratıcı endüstrilerin sınıflandırılmasına dair değerlendirme yer almaktadır. Bununla birlikte, Tablo 2 içerisinde yer alan sınıflandırmanın gelişmiş ülkelerin ulusal politikaları ile kültür ve yaratıcı endüstrilerin yönetişim modelleri içerisinde önemli bir etkiye sahip olan Ulus Üstü Örgütler ile Düzenleyici Otoritelerin yaklaşımlarının ağırlık taşıdığg belirtilmelidir. 
Tablo 2. Kültür ve Yaratıcı Endüstrilerin Sinıflandirlması (UNCTAD, 2010 ve Ghys 2010'dan aktaran http://www. ccp.gov.tr, 2013:16).

\begin{tabular}{|c|c|c|c|c|c|}
\hline $\begin{array}{l}\text { Sinıflandırma } \\
\text { Mantığı }\end{array}$ & $\begin{array}{l}\text { Sinıflandırma } \\
\text { Stratejisi Olmadan } \\
\text { Basit Listeleme }\end{array}$ & $\begin{array}{l}\text { Merkezde Kültür } \\
\text { ve Çevresinde } \\
\text { İșlevlerine Göre } \\
\text { Sinıflandırma }\end{array}$ & $\begin{array}{l}\text { Merkez Cevre } \\
\text { Ayrımı Olmaksızın } \\
\text { İșlevlere Dayanan } \\
\text { Sinıflandırma }\end{array}$ & $\begin{array}{l}\text { Kültür } \\
\text { Endüstrilerinde } \\
\text { Telif Hakkının } \\
\text { Rolüne Dayanan } \\
\text { Sınıflandırma }\end{array}$ & $\begin{array}{c}\text { Üretilen Kültürel } \\
\text { İçeriğin Doğasını } \\
\text { Ölçmeye Dayanan } \\
\text { Sinıflandırma İle } \\
\text { Toplumun } \\
\text { Kültürünün } \\
\text { Şekillenmesinde } \\
\text { Kültür Sektörlerinin } \\
\text { Etkisini Ölçmeye } \\
\text { Dayanan } \\
\text { Sınıflandırma }\end{array}$ \\
\hline $\begin{array}{c}\text { Kültürel } \\
\text { Endüstriler }\end{array}$ & $\begin{array}{l}\text { İngiliz Kültür, Medya } \\
\text { ve Spor Genel } \\
\text { Müdürlüğü }\end{array}$ & $\begin{array}{l}\text { Birleșmiș Milletler, } \\
\text { Ticaret ve Kalkınma } \\
\text { Komisyonu } \\
\text { (UNCTAD) }\end{array}$ & $\begin{array}{c}\text { Hollanda } \\
\text { Yaratıcı Hizmetler } \\
\text { Reklamcılık } \\
\text { Tasarım (Mimari } \\
\text { dâhil) } \\
\text { Yeni Medya }\end{array}$ & $\begin{array}{c}\text { Dünya Fikri } \\
\text { Haklar Örgütü } \\
\text { (WIPO) } \\
\text { Telif Hakkı }\end{array}$ & $\begin{array}{c}\text { Üretilen Kültürel } \\
\text { İçeriğin Doğasını } \\
\text { Ölçmeye Dayanan } \\
\text { Sınıflandırma }\end{array}$ \\
\hline $\begin{array}{l}\text { Reklamcıllk } \\
\text { Mimarlık } \\
\text { Antikalar } \\
\text { Görsel-İsittsel } \\
\text { Ürünler } \\
\text { Giysi ve Ayakkabı } \\
\text { Meslek Birlikleri } \\
\text { El Sanatları } \\
\text { Yaratıcı Sanatlar } \\
\text { Yaratıcı Hizmetler } \\
\text { Tasarım } \\
\text { Moda } \\
\text { Film ve Video } \\
\text { Ev Essyaları } \\
\text { Miras } \\
\text { Internet } \\
\text { Edebiyat } \\
\text { Müzeler ve } \\
\text { Kütüphaneler } \\
\text { Müzik } \\
\text { Yeni Medya } \\
\text { Gösteri Sanatları } \\
\text { Yayıncılık } \\
\text { Rekreasyon ve } \\
\text { Etkinlikler } \\
\text { Kültür Sektörleri için } \\
\text { Kaynaklar (boș kayıt } \\
\text { malzemeleri vb.) } \\
\text { Yazılım } \\
\text { Ses Kayıtları } \\
\text { Spor Türleri } \\
\text { Televizyon ve Radyo } \\
\text { Oyuncaklar }\end{array}$ & $\begin{array}{c}\text { Reklamcilık } \\
\text { Mimarlık } \\
\text { Sanat ve Antikalar } \\
\text { El Sanatları } \\
\text { Tasarım } \\
\text { Moda } \\
\text { Film ve Video } \\
\text { Müzik } \\
\text { Gösteri Sanatları } \\
\text { Yayıncılık } \\
\text { Yazılım } \\
\text { Televizyon ve } \\
\text { Radyo } \\
\text { Bilgisayar } \\
\text { Oyunları }\end{array}$ & $\begin{array}{c}\text { Miras } \\
\text { Kültürel Mekânlar } \\
\text { Geleneksel Kültürler } \\
\text { Sunumlar } \\
\text { Sanatlar } \\
\text { Gösteri Sanatları } \\
\text { Görsel Sanatlar } \\
\text { Medya } \\
\text { Görsel İsitsel } \\
\text { Ürünler } \\
\text { Yayıncılık } \\
\text { Basilı Yayınlar } \\
\\
\text { İslevsel } \\
\text { Ürünler } \\
\text { Yaratıcı } \\
\text { Hizmetler } \\
\text { Tasarım } \\
\text { Yeni Medya }\end{array}$ & $\begin{array}{c}\text { Medya ve Eğlence } \\
\text { Yazarlık } \\
\text { Film Endüstrisi } \\
\text { Yayıncılık } \\
\text { Sanatlar } \\
\text { Gösteri Sanatları ve } \\
\text { DVD / CD Satıș } \\
\text { Görsel Sanatlar } \\
\text { Rekreasyon ve } \\
\text { Etkinlik }\end{array}$ & $\begin{array}{c}\text { Merkez Telif } \\
\text { Hakkı Endüstrileri } \\
\text { Reklamcılık } \\
\text { Meslek Birlikleri } \\
\text { Film ve Video } \\
\text { Müzik } \\
\text { Gösteri Sanatları } \\
\text { Yayıncılık } \\
\text { Yazılım } \\
\text { Televizyon ve } \\
\text { Radyo } \\
\text { Görsel ve } \\
\text { Grafik Sanatlar }\end{array}$ & $\begin{array}{c}\text { Eș Merkezli Daireler } \\
\text { Modeli } \\
\text { Merkezi Yaratıcı } \\
\text { Sanatlar } \\
\text { Müzik } \\
\text { Gösteri Sanatları } \\
\text { Görsel Sanatlar } \\
\text { Diğer Merkezi } \\
\text { Kültürel } \\
\text { Endüstriler } \\
\text { Film } \\
\text { Müze } \\
\text { Kütüphaneler }\end{array}$ \\
\hline
\end{tabular}




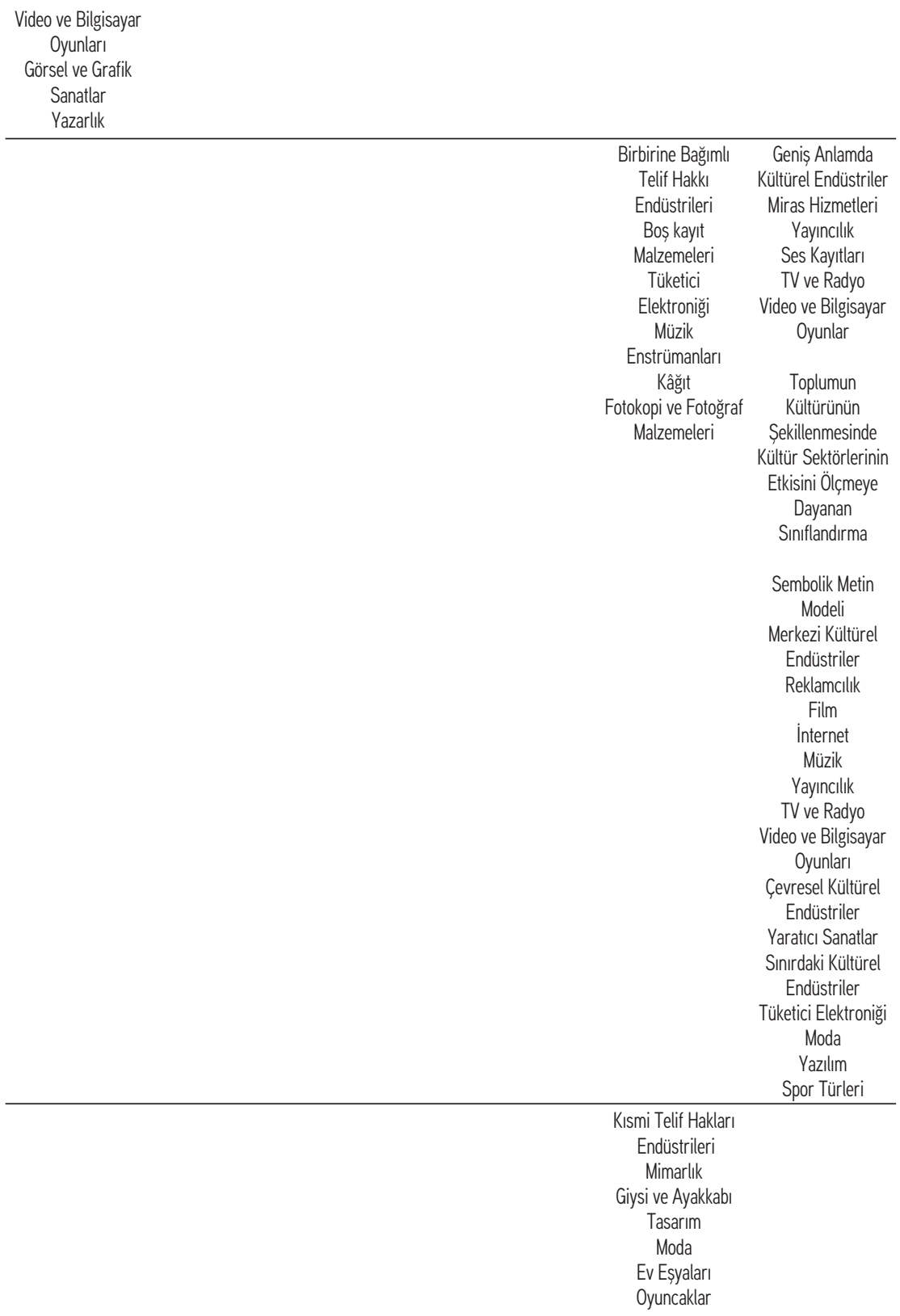

Tablo 2, kültür ve yaratıcı endüstrilere dair oldukça geniş bir bağlam oluştururken, bir yanda da kapitalizmin metalaştırma mantığının genişlediği bir 
alan olan bu endüstrileri görünür kılmaktadır. Gerçekten de, yukarıda yer alan geniş sınıflandırma içerisinde de değerlendirilebileceği üzere, sınıflandırmayı gerçekleştiren bütün kaynakların nerede ise ortak olarak yüksek bir meta değerinin ve hızlı bir metalaştırmanın yaygın olarak yer alabileceği alanlara yöneldiği görülür. Bununla birlikte söz konusu alanların önemli bir metalaştırma değeri içermesine rağmen, son kertesinde, gelişmekte olan ülkelerin değil ancak gelişmiş ülkelerin egemenliğini pekiştirebilecek alanları oluşturduğu da söylenmelidir. Bu açıdan bir diğer eleştiri ise; yukarıdaki sınıflandırmaların kültürel mirasın korunması ve geliştirilmesi yerine kültürün ticarileştirilmesine doğru bir eğilimi izlemesidir. Küresel düzeyde ele alındığında; kültür ve yaratıcı endüstrilerin dikkate değer bir mali büyüklük üretmiş olması önemli ise de henüz başlangıcından itibaren, kapitalizmin metalaşırıma mantığını egemen kılan yaklaşımların uzun dönemi içerisinde, gelişmiş ve gelişmekte olan ülkeler arasında yeni eşitsizlik biçimlerini egemen kılma potansiyeli bulunmaktadır. Nicholas Garnham (2006: 17); yaratıcı endüstri politikalarının açık bir biçimde 1980'li ve 1990'lı yılların karakteristik niteliklerini birlikte taşıdığını belirler. Garnham’a göre; neo liberalizmin özelleştirme ve ticarileştirme eğilimi, yaratıcı endüstrilere de yansımıştır. Bu doğrultuda, yaratıcı endüstrilere ilişkin yönetişim politikalarının da yine neo liberal küreselleşme döneminin gölgesinde, gelişmiş ülkelerden gelişmekte olan ülkelere doğru bir küresel kültürel akış mimarisi tasarımını içerdiği söylenmelidir. Kültür ve yaratıcı endüstrilere dair bir diğer önemli belirleme ise; "yeni" bir küreselleşme ve küresel kültürel akış sürecinin olanaklı olduğunu görünür kılmasıdır. Küreselleşme sürecinin derinleşmesiyle birlikte, emtia ticaretinden gittikçe küresel ekonomi politikaların özel bir uğrağı olarak, küresel ticaretin kültürel hizmet ve ürünlerine doğru genişlemesi küresel düzeyde "kültür ve yaratıcı endüstri" ticaretini görünür kılmaktadır. 2017 yılında ilk kez gerçekleştirilen "Kültürel ve Yaratıcı Endüstrilerin İlk Küresel Harita Çalısması" (http://www.worldcreative. org, 2017: 5) bu açıdan genel bir fikir verebilme kapasitesine sahiptir. Örneğin 2017 yılında, küresel olarak kültürel ve yaratıcı endüstrilerin 2.250 milyar dolarlık bir mali büyüklüğe ulaştığı ve bu yönüyle küresel düzeyde, 1.570 milyar dolarlık gelir elde eden, telekomünikasyon sektörünü geride bıraktığı rapor içerisinde belirtilmiştir. Ulaştığı mali büyüklüğün yanı sıra, istihdam potansiyeli ile de dikkat çeken kültürel ve yaratıcı endüstrilerin, bu dönem içerisinde, dünya nüfusunun \%1'i olan 29.5 milyon kişiye is- 
tihdam olanağı sağladığı belirlenmiştir. Ülkelerin refah ve istihdamlarına ilişkin önemli bir kaynak olarak ortaya çıkan kültür ve yaratıcı endüstrilerin bölgelere göre istihdam ve refah seviyelerine katkısı aşağıdaki Tablo 3 içerisinde yer almaktadır.

Tablo 3. Küresel ve Yaratıcı Endüstrilerin Bölgelere Göre Oluşturduğu Mali Büyüklük (http://www.worldcreative.org, 2017: 5).

\begin{tabular}{|c|c|c|c|}
\hline $\begin{array}{l}\text { Yaratıcı } \\
\text { Endüistri } \\
\text { Ticaretindeki } \\
\text { Bölgeler }\end{array}$ & $\begin{array}{l}\text { Kültürel / Yaratıcı } \\
\text { Endüstrilerin Mali } \\
\text { Büyülklüğ̈̈ }\end{array}$ & $\begin{array}{l}\text { Kültürel / Yaratıcı } \\
\text { Endüstrilerin } \\
\text { Kitalara Göre } \\
\text { Oluşturduğu } \\
\text { İstihdam }\end{array}$ & $\begin{array}{l}\text { İstihdamın } \\
\text { Yoğunlaştığı } \\
\text { Alanlar }\end{array}$ \\
\hline $\begin{array}{l}\text { Afrika ve } \\
\text { Ortadoğu }\end{array}$ & $\begin{array}{l}\text { Küresel endüstri gelirle- } \\
\text { rinin \%3'ü bu bölgede } \\
\text { oluşturulmuştur. } 58 \text { mil- } \\
\text { yar dolarlık bir bütçeye } \\
\text { sahiptir. }\end{array}$ & $\begin{array}{l}\text { Küresel düzeyde, } \\
\text { istihdamın \%8'i } \\
\text { bu bölgede oluştu- } \\
\text { rulmuştur. }\end{array}$ & $\begin{array}{l}\text { Etnik Müzik } \\
\text { ve Sinema } \\
\text { (Nollywood) }\end{array}$ \\
\hline Asya-Pasifik & $\begin{array}{l}\text { Küresel kültür ve yara- } \\
\text { tıcı endüstri gelirlerinin } \\
\text { \%33’ü bu Bölge içerisin- } \\
\text { de elde edilmiştir. }\end{array}$ & $\begin{array}{l}\text { Küresel düzeyde } \\
\text { istihdamın } \\
\text { \%43'ü bölgede } \\
\text { gerçekleşmiştir. }\end{array}$ & $\begin{array}{l}\text { Küresel kitap } \\
\text { üretimi ve } \\
\text { yazılı basın. }\end{array}$ \\
\hline Avrupa & $\begin{array}{l}\text { Küresel kültür ve yara- } \\
\text { tıcı endüstri gelirlerinin } \\
\% 32 \text { 'si olan } 709 \text { milyar } \\
\text { dolar Avrupa'dan elde } \\
\text { edilmiştir. }\end{array}$ & $\begin{array}{l}\text { Küresel düzeyde } \\
\text { istihdamın \%26'sı } \\
\text { bölgede gerçekleş- } \\
\text { miştir. }\end{array}$ & $\begin{array}{l}\text { Müzecilik } \\
\text { ve yaratıcı } \\
\text { şehirler ağı. }\end{array}$ \\
\hline $\begin{array}{l}\text { Latin Amerika } \\
\text { ve Karayipler }\end{array}$ & $\begin{array}{l}\text { Kültür ve yaratıcı endüst- } \\
\text { rilerden elde edilen ge- } \\
\text { lirin \%6'sı, bu bölgeden } \\
\text { elde edilmiştir. }\end{array}$ & $\begin{array}{l}1.9 \text { milyon kişiye } \\
\text { istihdam olanağ } \\
\text { sağlanmıştır. }\end{array}$ & $\begin{array}{l}\text { Unesco } \\
\text { tarafından } \\
\text { "dünya mi- } \\
\text { rası" olarak } \\
\text { arkeolojik } \\
\text { siteler. Çok } \\
\text { uluslu med- } \\
\text { ya şirketleri. }\end{array}$ \\
\hline Kuzey Amerika & $\begin{array}{l}\text { Kültür ve yaratıcı en- } \\
\text { düstri bileşkesinden elde } \\
\text { edilen gelirin } \% 28^{\prime} i \\
\text { bölgeden elde edilmiştir. }\end{array}$ & $\begin{array}{l}\text { Küresel } \\
\text { istihdamının } \\
\text { \%16'sı bu bölge- } \\
\text { dedir. }\end{array}$ & $\begin{array}{l}\text { Dijital içe- } \\
\text { rik. Görsel } \\
\text { İşitsel Yayın- } \\
\text { cilık. }\end{array}$ \\
\hline
\end{tabular}


Tablo 3 içerisindeki veriler; gelişmekte olan ülkeler açısından değerlendirildiğinde, kültür ve yaratıcı endüstrilerin söz konusu ülkeler için hem "olanakları" ve "firsatları" ancak aynı zamanda "tehditleri” ve "eşitsizlikleri" görünür kıldığı söylenmelidir. Gerçekten de, ülkeleri eşsiz kılan somut olmayan kültürel miraslarının sunduğu olanakların hemen yanında gelişmekte olan ülkelerin bilgi toplumuna geçiş sürecine henüz hazırlıklı olmadıkları Tablo 3 içerisinde, bölgesel ayrımlar dikkate alındığında, söylenebilir. Christiaan De Beukelaer (2014: 233); gelişmekte olan ülkelerin sürdürülebilir kalkınma stratejilerinin önemli bir unsuru olarak kültür ve yaratıcı endüstriler politikalarını geliştirdiklerini belirtir. Aşağıdaki alt bölüm içerisinde gelişmekte olan ülkelerde kültür ve yaratıcı endüstriler, kamu politikaları bağlamında ele alınmaktadır.

\section{Gelişmekte Olan Ülkelerde Kültür ve Yaratıcı Endüstriler}

Afrika’nın, kültürel sektörleri için "Pan-Afrika” şemsiye örgütü olarak kurulan "Arterial Ağının”, 2011 yılından itibaren, düzenli olarak, Afrika Yaratıcı Ekonomi Konferanslarını düzenlemesi gelişmekte olan ülkelerin kültür ve yaratıcı endüstrileri için ilk örneği oluşturmaktadır. Afrika’nın bölgesel olarak gerçekleştirdiği çalışmaların yanı sıra gelişmekte olan ülkelerin tekil örnekleri de kültür ve yaratıcı endüstrilerin anlamlı bir dizi proje ve çalışmanın odağına yerleştiğini görünür kılmaktadır. Lübnan'ın başkenti Beyrut'un "yaratıcı şehir" statüsüne alınması ve kentsel yerleşimlerde kültürel ekonomilerin canlandırılmasına ilişkin bir diğer örneği oluşturmaktadır. Bu örneklerin yanı sıra, gelişmekte olan ülkelerin aralarında kültür ve yaratıcı endüstrilere dair yeni ulus üstü örgütlenmeleri geliştirmeleri ise bu bağlamda dikkat çeken bir diğer örneği oluşturmaktadır. Pasifik Ülkeleri Sekreterliği'nin kurulması, ulus üstü ağların nasıl kurulduğuna dair bir örneği oluşturmaktadır. Bununla birlikte, kültürün bir ticarileştirme sürecinin odağında yer alıp alamayacağı tartışmalı olsa da, kültürel üretimin ya da kültürel bir değer taşıyan metaların küresel ticarete konu olması yirminci yüzyılın özel bir uğrağını oluşturur (Smith 2006: 14).

Neo liberal politikaların hegemonyası altında, gelişmekte olan ülkelerin nerede ise yok sayıldığı küresel kültürel akış yerine, kültür ve yaratıcı endüstriler politikaları ve yönetişim modelleri eliyle gelişmekte olan ülkelerin, küresel kültürel akışsüreci içerisinde genişleyen bir yer edinebilmesi olanaklı hale 
gelmiştir. Lee Artz (2015: 31-32), Nijerya film endüstrisinin, Nollywood, üretilen ve dağıtılan film sayısı itibari ile küresel olarak Hindistan film endüstrisinin, Bollywood, ardından ikinci olduğunu belirtir. Nijerya film endüstrisinin, küresel kültürel akış içerisindeki konumu, gelişmekte olan ülkelerde kültür ve yaratıcı endüstrilerinde uluslarasılaşma eliyle nasıl bir yer edinebileceğine dair özel bir örnek olarak dikkat çekmektedir. Gelişmekte olan ülkelerin, kültür ve yaratıcı endüstrileri eliyle küresel kültürel akış içerisinde edindikleri yer, henüz gelişmiş ülkelerin bu alandaki konumunun ardında kalmakla birlikte, özel bir dikkat çekmektedir. Gerçekten de, küresel olarak değerlendirildiğinde Birleşmiş Milletler Ticaret ve Kalkınma Konseyi'nin gelişmekte olan ülkelerde yaratıcı ekonomi raporu içerisinde belirtildiği üzere, gelişmekte olan ülkelerin gelişmiş ülkeleri 2012 yılında geçmeleri, kültür ve yaratıcı endüstriler eliyle küresel kültürel akışın değişen mimarisini görünür kıldığı çalışma olarak kayda değerdir. Aşağıdaki Tablo 4 içerisinde, genel bir karşılaştırma ve bunun ötesinde gelişmekte olan ülkelerin kültür ve yaratıcı endüstriler alanındaki ilerlemesini görünür kılabilmek için 2010 yllı dönemi içerisinde; gelişmiş, gelişmekte olan ve geçiş sürecindeki ülkelerin kültür ve yaratıcı endüstriler içerisindeki ihracatı verilmektedir. Bununla birlikte Tablo 4 ve ardından gelen Tablo 5 içerisinde yer alan verilere ilişkin bir açıklama yapılması gerekmektedir. Kültür ve yaratıcı endüstriler içerisinde üretilen değerlere ilişkin hem gelişmiş hem de gelişmekte olan ülkelerin potansiyellerinin birlikte değerlendirildiği çalışmaların oldukça sınırlı olması bir yana, çalışma içerisinde söz konusu iki tablo, kültür ve yaratıcı endüstrilerin ilk dönemi ile sonraki dönemleri arasında bir karşılaştırma yapılmasına olanak tanıdığı için kullanılmıştır. Gerçekten de, gelişmekte olan ülkeler için kültür ve yaratıcı endüstrilerin ilk dönemi, ihracat açısından, gelişmiş ülkelere göre oldukça sınırlı bir uzam oluşturmuşken, Tablo 5 içerisinde de yer aldığı üzere, sonraki yıllarında gelişmekte olan ülkelerin kültür ve yaratıcı endüstrileri alanında gelişmiş ülkeleri geçtikleri görülmektedir. 
Tablo 4. Küresel Olarak Kültür ve Yaratıcı Ürünler İhracatı (UNCTAD 2010: 308-311'den aktaran Beukealer 2014: 235. İhracat verileri, milyon dolar düzeyindedir).

\begin{tabular}{ccccc}
\hline Ürün Grubu & $\begin{array}{c}\text { Dünya } \\
\text { Geneli }\end{array}$ & $\begin{array}{c}\text { Gelişmiş } \\
\text { Ülkeler }\end{array}$ & $\begin{array}{c}\text { Gelişmekte } \\
\text { Olan Ülkeler }\end{array}$ & $\begin{array}{c}\text { Geçiş Sürecin- } \\
\text { deki Ülkeler }\end{array}$ \\
\hline Sanat ve Zanaat & $32,323.00$ & $11,443.00$ & $20,715.00$ & 164.00 \\
\hline Görsel İşitsel & 811.00 & 726.00 & 75.00 & 10.00 \\
\hline Tasarım & $241,972.00$ & $117,816.00$ & $122,439.00$ & 1716.00 \\
\hline Yeni Medya & 27.75 & $13,248.00$ & $14,423.00$ & 82.00 \\
\hline $\begin{array}{c}\text { Performans } \\
\text { Sanatları }\end{array}$ & $26,136.00$ & $22,539.00$ & 3323.00 & 274.00 \\
\hline $\begin{array}{c}\text { Yayıncılık } \\
48,266.00\end{array}$ & $38,753.00$ & 8138.00 & 1376.00 \\
\hline Görsel Sanatlar & $29,730.00$ & $22,578.00$ & 7097.00 & 56.00 \\
\hline $\begin{array}{c}\text { Yaratıcı Ürün- } \\
\text { ler Toplamı }\end{array}$ & $\mathbf{4 0 0 , 9 9 2 . 0 0}$ & $\mathbf{2 2 7 , 1 0 3 . 0 0}$ & $\mathbf{1 7 6 , 2 1 1 . 0 0}$ & $\mathbf{3 6 7 8 . 0 0}$ \\
\hline
\end{tabular}

Tablo 4 içerisinde sunulan veriler değerlendirildiğinde, gelişmiş ve gelişmekte olan ülkeler arasındaki eşitsiz bir ilişkinin varlığından söz edilmesi anlamlı olacaktır. Öyle ki, gelişmiş ülkelerin yaratıcı sektörlerin genelinde gerçekleştirdikleri ihracatın, gelişmekte olan ülkelerin toplam ihracatının nerede ise iki katına ulaşması söz konusu eşitsizliği görünür kılmaktadır. Ancak bu durum, kültür ve yaratıcı endüstrilerin ilk dönemi için geçerlidir. Gerçekten de, gelişmekte olan ülkelerin, 2012 yılından itibaren gelişmiş ülkeleri ihracat alanında geçtiği, hatta Türkiye'nin söz konusu tarihte en çok ihracat gerçekleştiren 18. ülke olduğu, belirtilmelidir. Aynı Rapora göre (http:www.unctad.org, 2015: 1); gelişmekte olan ülkeler 2012 yılında küresel kültür ve yaratıcı endüstriler ihracatında $\% 57$ gibi önemli bir pay alırken, gelişmiş ülkelerin payı \%42'de kalmıştır. Bununla birlikte, aralarında Türk Cumhuriyetleri'nin yer aldığı "geçiş ekonomileri" ancak küresel düzeyde $\% 1$ oranında bir ihracata sahip olmuştur ki böylesi bir durum, kültür ve yaratıcı endüstriler içerisindeki yukarıda sözü edilen "eşitsizliği” görünür kılmaktadır. Gerçekten de, bu dönem içerisinde gelişmiş ülkelerin ithalatı ancak \%69 düzeyinde gerçekleşirken, geçiş ekonomileri toplam ihracat oranlarından (\%1) daha fazla bir ithalat (\%3) gerçekleştirmiştir. Aşă̆ıdaki Tablo 5 içerisinde, küresel olarak kültür ve yaratıcı endüstriler içerisinden en yoğun ihracat gerçekleştiren ilk 20 ülkeye yer verilmiştir. 
Tablo 5. Küresel Düzeyde Kültür ve Yaratıcı Endüstriler İhracatında İlk 20 Ülke (http://www.unctad.org, 2015: 4).

\begin{tabular}{|c|c|c|c|c|c|c|}
\hline Sira & $\begin{array}{l}\text { İhracatçı } \\
\text { Ülke }\end{array}$ & $\begin{array}{r}\text { Gerçekle } \\
\text { Değeri (I } \\
\text { l }\end{array}$ & $\begin{array}{l}\text { sen İhracat } \\
\text { Milyon Do- } \\
\text { ar) }\end{array}$ & Sira & $\begin{array}{c}\text { Pazar } \\
\text { Payı } \\
(\%)\end{array}$ & $\begin{array}{l}\text { Gelişim } \\
\text { ve Deği- } \\
\text { şim Ora- } \\
\text { nı (\%) }\end{array}$ \\
\hline 2012 & & 2012 & 2003 & 2003 & & $\begin{array}{c}2003- \\
2012 \\
\text { Yılları } \\
\text { Arasında }\end{array}$ \\
\hline 1 & $\begin{array}{c}\text { Çin Halk } \\
\text { Cumhuriyetleri }\end{array}$ & 151,182 & 38,180 & 1 & 31,91 & 15 \\
\hline 2 & $\begin{array}{l}\text { Amerika Birle- } \\
\text { şik Devletleri }\end{array}$ & 37,844 & 17,887 & 3 & 7.99 & 8 \\
\hline 3 & Hong Kong & 34,197 & 23,637 & 2 & 7.22 & 4 \\
\hline 4 & Almanya & 28,179 & 16,519 & 4 & 6.06 & 7 \\
\hline 5 & Hindistan & 25,846 & 4,349 & 12 & 5.46 & 20 \\
\hline 6 & İngiltere & 23,083 & 14,520 & 5 & 4.87 & 4 \\
\hline 7 & Fransa & 19,774 & 10,137 & 6 & 4.17 & 7 \\
\hline 8 & İsviçre & 13,073 & 5.135 & 9 & 2.76 & 11 \\
\hline 9 & Singapur & 11,344 & 1.866 & 18 & 2.39 & 26 \\
\hline 10 & Hollanda & 9,395 & 4.750 & 10 & 1.98 & 9 \\
\hline 11 & Tayvan & 9,380 & Ölçüm Yok & & 1.98 & 18 \\
\hline 12 & Japonya & 7,721 & 3.823 & 14 & 1.63 & 10 \\
\hline 13 & Belçika & 7,611 & 6.469 & 8 & 1.61 & 2 \\
\hline 14 & Türkiye & 7,361 & 2,303 & 16 & 1.55 & 12 \\
\hline 15 & Tayland & 6,460 & 2,928 & 15 & 1.36 & 10 \\
\hline 16 & Kanada & 6,254 & 9,515 & 7 & 1.32 & -6 \\
\hline 17 & İspanya & 5,922 & 4,616 & 11 & 1.25 & 2 \\
\hline 18 & Malezya & 5,810 & 1,951 & 17 & 1.23 & 14 \\
\hline 19 & Kore & 5,763 & 3,967 & 13 & 1.22 & 6 \\
\hline 20 & $\begin{array}{c}\text { Çek } \\
\text { Cumhuriyeti }\end{array}$ & 5,614 & 1,793 & 19 & 1.18 & 15 \\
\hline
\end{tabular}


Tablo 5 içerinde yer alan veriler değerlendirildiğinde, gelişmekte olan ülkelerin kültür ve yaratıcı endüstriler içerisinde gittikçe genişleyen bir yer edindiği açık bir biçimde gözlenmektedir. Gelişmiş ülkeler ise, 2003-2012 yılları arasında kayda değer bir ihracat gerçekleştirmiş olmalarına rağmen büyüme oranları, gelişmekte olan ülkelerin altında kalmıştır. Tablo 5 içerisindeki veriler üzerinden değerlendirildiğinde, Türkiye'nin 2003-2012 yılları arasında önemli bir gelişme gösterdiğini belirtmek gerekmektedir. 2003 yllında küresel olarak 16. olan konumunun, 2012 y1lında 12.'liğe yükselmesi ve gelişiminin \%12 düzeyinde gerçekleştirilmesi kayda değer ilerlemeyi görünür kılmaktadır. Bununla birlikte; Türkiye ve Türk Cumhuriyetleri'nin sürdürülebilir kalkınma doğrultusunda sistemli bir strateji ve eylem planı izlemesi gerekliliğinin de belirtilmesi gerekir. Bu doğrultuda bir sonraki alt bölüm, Türkiye ve Türk Cumhuriyetleri için kültür ve yaratıcı endüstrilerinin yönetişimi için bir dizi öneriyi geliştirmeyi amaçlamıştır.

\section{Kültür ve Yaratıcı Endüstrilerin Yönetişimi İçin Türk Dünyası İçin Öneriler}

Türk Dünyası'nın tarihin hafızasından süzülerek gelen özel bir konumu bulunmasına rağmen, küresel kültürel akış içerisinde varlı̆̆ını gösterebilmesi ve bulunduğu yeri genişletmesi hem kültürel mirasının korunması ve geliştirilmesi adına tarihe karşı bir sorumluluğunu, hem de Türk Dünyası'nın refah ve istihdam oranlarının yükseltilmesi adına bir görevini de oluşturmaktadır. Bu alt bölüm içerisinde, Türk Dünyasının kültür ve yaratıcı endüstrileri için bir dizi önerinin geliştirilmesi amaçlanmıştır. Bu doğrultuda, Türk Dünyasının bütününü kapsayan projelere ihtiyaç duyulduğunu belirtmek gerekir. Gerçekten de, örneğin Avrupa Birliği "yaratıcı şehirler ağı” projesi içerisinde 2010 yılında Türkiye'den İstanbul'un, Almanya ve Macaristan'daki şehirlerle birlikte, "Avrupa Kültür Başkenti” unvanını almasına rağmen (http://www.bbc.com, 2010: 1) böylesi bir unvanın ülkenin gelişmişlik düzeyi için ne denli bir etkiye sahip olduğu tartışmalıdır. Birleşmiş Milletler Eğitim, Kültür ve Bilim Örgütünün "yaratıcı şehirler ağı” projesi ise yeni başlamış olmasına rağmen, Türk Dünyası için de anlamlı olarak değerlendirilebilecek bir girişim olarak değerlendirilmelidir. 2017 yılı içerisinde; Türkiye’den İstanbul'un tasarım, Kütahya’nın zanaat ve geleneksel halk sanatları, Hatay'ın gastronomi, Kazakistan'dan ise Almaata Şehri'nin müzik alanında yer aldığı Birleşmiş Milletler yaratıcı şehirler ağı 
içerisinde, Türk Dünyasından daha fazla şehrin katılımının sağlanması, en azından bu çalışmanın yazarı tarafından, düşünülmektedir (http://en.unesco. org, 2017:1). Yaratıcı şehirler ağı projesinin, kültürel mirasın korunması ve ülkelerin küresel kültürel akış içerisinde yer edinebilmesi için anlamlı olsa da gelişmekte olan ülkelerin kültür ve yaratıcı endüstriler alanında geliştirilmesi gereken politika alanlarının bulunduğu da söylenmelidir. Terry Flew (2012: 57); Birleşmiş Milletler Ticaret ve Kalkınma Konseyi tarafından işaret edilen, gelişmekte olan ülkelerde kültür ve yaratıcı endüstri politika alanlarını aşağıdaki gibi maddeleştirmektedir. (1) yeni enformasyon ve iletişim teknolojilerine erişimin sağlanması ve geliştirilmesi. (2) standart kredi kaynaklarına erişmekte önemli problemler yaşayan küçük ölçekli kültür ve yaratıcı endüstriler alanındaki girişimcilerin, finansman kaynaklarına ulaşmasının sağlanması ve geliştirilmesi. (3) kültürel ajanslar ve bakanlıkların, özellikle söz konusu endüstrilerin ve teknolojilerin geliştirilmesiyle doğrudan ilgili olan kamu kuruluşları dışında yer alan sektör temsilcilerini ile esnek ve bütünleşmiş, sürdürülebilir ilişki kurma olanaklarının sağlanması ve geliştirilmesi. (4) yaratıcı sanatçıların gelir elde edebilmesi için korsan uygulamalarla mücadele edilmesi ve koleksiyon ajanslarının geliştirilmesi. Son olarak ise (5) öncelikle küçük ölçekli ve bağımsız kültür üreticileri olmak üzere, yaratıcı endüstri kümeleşmelerinin desteklenmesi, geliştirilmesi ve söz konusu girişimciler için kaynaklara erişimin sağlanması yönündeki öneriler, gelişmekte olan ülkeler için kültür ve yaratıcı endüstriler alanında öncelikli politika alanları olarak öne çıkmaktadır. Gerçekten de, ortak kültürel değerler üzerine yükselen Türk Dünyasının kültür ve yaratıcı endüstrilerinin ilk düzeyde "uluslararasılaşması" ve ulus ötesi yönetişim ağının kurulması, tıpkı küresel düzeyde gelişmekte olan ülkelerin oluşturduğu "çatı örgütler" gibi, kapsamlı bir yönetişim modelinin geliştirilmesi için anlamlı olacaktır. Bu doğrultuda, Türk Dünyasının kültür ve yaratıcı endüstrileri içerisinde "uluslarasılaşma" bir diğer seçeneği oluşturmaktadır. Kore'nin, Hallyu 1.0 ve Hallyu 2.0 projelerinde örnekleri görüldüğü üzere (Lee 2015: 172), Türk Dünyasının Türk Devletleri'nin d1şında yer alan nüfusuna kültür ve yaratıcı endüstrileri ile birlikte açılması anlamlı bir girişim olarak öne çımaktadır. Türk Dünyası ülkeleri için bir diğer yönetişim unsuru ise yeni enformasyon ve iletişim teknolojilerinin ithalatçısı olmak yerine marka sahibi üreticisi olmayı tercih etmektir. Aşağıdaki Tablo 6 içerisinde, Türkiye ve Türk Cumhuriyetleri'nin internet erişim oranları ve toplam internet kullanıcısı sayısı yer almaktadır. 
Tablo 6. Türk Dünyasinın Belirli Ülkelerinde İnternet Erişim Oranları (http://www.internetworldstats.com, 2018 yılı verilerinden yararlanılarak araştırmacı tarafından derlenmiştir).

\begin{tabular}{|c|c|c|c|c|c|}
\hline Ülke İsmi & Nüfusu & $\begin{array}{c}\text { İnternet } \\
\text { Kullanıcıları }\end{array}$ & $\begin{array}{l}\text { İnternet } \\
\text { Erişimi }\end{array}$ & $\begin{array}{c}\text { Bölgesinde- } \\
\text { ki Internet } \\
\text { Kullanıcı- } \\
\text { larına Göre } \\
\text { Oranı }\end{array}$ & $\begin{array}{c}\text { Facebook } \\
\text { Kullanic1- } \\
\text { ları }\end{array}$ \\
\hline Türkiye & $80,417,526$ & $56,000,000$ & $\% 69.6$ & $\% 8.5$ & $56,000,000$ \\
\hline Azerbaycan & $9,973,697$ & $7,799,431$ & $\% 78.2$ & $\% 0.4$ & $1,800.000$ \\
\hline Kazakistan & $18,064,470$ & $13,873,513$ & $\% 76.8$ & $\% 0.7$ & $1,500,000$ \\
\hline Tacikistan & $8,858,115$ & $1,813,256$ & $\% 20.5$ & $\% 0.1$ & 84.000 \\
\hline Türkmenistan & $5,502,586$ & 989,915 & $\% 18.0$ & $\% 0.1$ & 15,000 \\
\hline Özbekistan & $30,690,914$ & $15,453,227$ & $\% 50.4$ & $\% 0.8$ & 530,000 \\
\hline $\begin{array}{l}\text { Yaklaşık } \\
\text { Nüfus } \\
\text { Toplamı }\end{array}$ & $153,507,308$ & & & & \\
\hline $\begin{array}{c}\text { Yaklaşık } \\
\text { İnternet } \\
\text { Kullanıcısı } \\
\text { Toplamı }\end{array}$ & & $95,909,342$ & & & \\
\hline
\end{tabular}

Türk Dünyasının kültür ve yaratıcı endüstrilerin ekosistemi içerisinde 95 milyonun üzerindeki gücü, yeni enformasyon ve iletişim teknolojilerinin yalnızca ithalatçısı olarak değil bununla birlikte üreticisi olarak da yer alınabilmesi için güçlü bir gerekçe oluşturmaktadır.

Yaratıcı endüstriler ekosistemi içerisinde; bilgi toplumu mirasının, bireysel yetenek, yaratıcılık ve fikri haklar temelinde geliştirilmesi gereken "nitelikli" insan kaynağına duyulan ihtiyacın vurgulanması gerekir. Yukarıda genel olarak değerlendirilen büyüklükteki bir nüfus için yetenek ve niteliğe dayanan yeni eğitim kurumlarının, eğitimin tüm düzeylerinde yaygınlaştırılması ya da farklı ifade edildiğinde eğitimin, Türk Dünyası içerisinde küreselleşmesi ve uluslararasılaşması unsurlarının yeniden düşünülmesi anlamlı olacaktır. Bununla birlikte, Türk Dünyası kültür ve yaratıcı endüstrilerinin yönetişimi için bir diğer önemli bir düşünce Nebi Özdemir'in (2012: 366) katkısı ile 
geliştirilmektedir. Özdemir’in işaret ettiği üzere kültür turizmi Türk Dünyası için mesafelerin ve dil engellerinin aşlabilmesi adına önemli bir olanak olarak ortaya çıkmaktadır. Bu doğrultuda, Türk Dünyası düşünce, bilim ve kültür alanlarındaki, Yunus Emre, Nasrettin Hoca gibi öncü temellinde kültür turizminin desteklenmesi önemli bir diğer olanağı sunmaktadır.

\section{Sonuç}

Kültür ve yaratıcı endüstrilerin; Türk Dünyası özelinde değerlendirilmesini amaçlayan bu çalışma içerisinde, gelişmekte olan ülkeler perspektifinden bir "olanaklar" ve "sorunlar" evreni olarak sözü edilen endüstrilere yeniden değer biçilmiştir. Kültür ve yaratıcı endüstriler ekosistemi; gelişmiş ülkelerden daha çok "gelişmekte olan" ve "geçiş ekonomilerindeki" ülkeler için oldukça anlamlı bir tartışma zemini oluşturmaktadır.

Ülkelerin, kültür ve yaratıcı endüstrileri aracıllğı ile küresel kültür akışı içerisinde yer alabilmesi yalnızca yeni istihdam ve refah kaynakları olarak değil bununla birlikte uluslararası "imaj" ve "algı" yönetimi için de anlamlıdır. O denli ki, neo liberal politikalar eliyle inşa edilen 1980'li yıllar boyunca gelişen küreselleşme sürecinin, ağıllıklı olarak Amerika Birleşik Devletleri merkezli, sınırlı sayıdaki, kültür endüstrisi aracılığıyla yönlendirilen bir küresel kültürel akışın bir "tek tipleştirme" ve "bağımlılık" denklemini ortaya çıkarttığı artık bir sır değildir. Kültür ve yaratıcı endüstriler ekosistemi içerisinde farklı bir küreselleşme sürecinin olabileceğini görülmesi bu doğrultuda anlamlı bir uğrağı oluşturmaktadır. Gerçekten de, önceki alt bölümler içerisinde değerlendirildiği üzere Hollywood'un yerini gittikçe Bollywood ve Nollywood'un alması öte yandan Kore'nin sistemli projesi olan Hallyu aracilığı ile birlikte kültür ve yaratıcı endüstrilerin yükselen örneği olarak öne çıkması dikkate alındığında aslında görülen; daha yaşanabilir ve kültürel açıdan daha zengin bir dünyanın varlığıdır. Bununla birlikte, bu çalışmanın odağında yer alan Türk Dünyası kültür ve yaratıcı endüstrilerinin gelişmesine dair bir diğer önemli sorumluluk, siyasa düzeyinde olduğu kadar hatta belki de daha da önemli olarak, akademik çalışmaların da önemli bir görevidir.

Bir önceki alt bölüm içerisinde yer aldığı üzere, kültür ve yaratıcı endüstrilerin siyasa düzeyindeki bir yönetişim modeli ekseninde ele alınması tek başına yeterli değildir. Gerçekten de, siyasa düzeyindeki ilginin yanı sıra 
akademik düzeyde de sözü edilen endüstrilere dair bir ilginin, en azından, "uyandırılması" gerekmektedir. Öyle ki, Türk Dünyası akademisyenlerinin birlikte gerçekleştirebilecekleri ortak projelere her zamankinden daha çok ihtiyaç duyulmaktadır. Bu doğrultuda, özellikle, kültür ve yaratıcı endüstrilerin Türkiye ve Türk Cumhuriyetleri'ndeki kümeleşmesi ve böylesi bir kümeleşme üzerinden ülkelerin genel refahına nasıl bir katkı sunulabileceği sonraki dönemlerin akademik tartısmaları içerisinde yer almalıdır. Öte yandan, Türk Dünyası akademisyenlerini kültür ve yaratıcı endüstrileri yeniden düşünmeye davet eden uluslararası kongrelerin düzenlenmesinin anlamlı bir katkı olacağı bu çalışmanın yazarı tarafından düşünülmektedir. Kültür ve yaratıcı endüstrilerin geniş doğası dikkate alındığında söz konusu endüstrilere dair araştırmaların, karşılıklı paylaşımların anlamlı olduğu söylenmelidir.

$\mathrm{Bu}$ çalışmanın odağında yer alan Türk Dünyası ülkeleri, kültür ve yaratıcı endüstrileri aracılığı ile kültürlerini, küresel kültürel akışın öncü "aktörleri” olarak bütün bir "küreye" yaydıkça, refah ve istihdamın yeni kaynaklarını değil refahı da anlamlı kılan bir kültürel doygunluğu oluşturacak ve belki de kültür ve yaratıcı endüstriler ekosistemini anlaşılır kılacaktır. Ancak böylesi bir anlamlı kılma çabası, yukarıda da sözü edildiği üzere toplumun geniş kesimlerinin, kültür ve yaratıcı endüstriler içerisinde yer alan çalışanların, politika düzeyinde karar alıcıların olduğu kadar, hatta böylesi katkılardan daha da önemli olarak, Türk Dünyası akademisyenlerinin önemli bir görevi ve sorumluluğunu oluşturmaktadır. Üstelik kültür ve yaratıcı endüstriler içerisinde akademisyenlerin gerçekleştirebileceği geniş bir tartışma alanı hem pratikte hem de kuramsal olarak geniş bir düzeyde bulunmaktadır. Örneğin, Türk Dünyası'nda girişimcilik, yeni fikirlerin geliştirilmesi, karşılaştırmalı politika analizlerinin ve yönetişim modellerinin tartışılması, özellikle gelişmiş ülkelerde örnekleri yoğun olarak görülen "fikirler için kuluçka merkezlerinin” ve araştırma olanaklarının geliştirilmesi bu anlamda önem taşımaktadır. Bunun yanı sıra, özellikle bilgi toplumu tartışmaları ve bilgi toplumu dönüşümü düşünüldüğünde "yetenek, yaratıcılık ve fikri haklara dayalı” kariyer merkezlerinin Türk Dünyası içerisinde geliştirilmesi bu çalışmanın ardından Türk Dünyası akademisyenlerinin ilgisine sunulmaktadır. Türk Dünyası; bir bütün olarak değerlendirildiğinde, böylesi bir ekosistemi anlamlı kılabilecek güce sahiptir. 


\section{Açıklamalar}

1 Kültür ve yaratıcı endüstrilerin yönetişim modellerinde özellikle de Avrupa Birliği siyasa gündemi içerisinde (http://www.keanet.eu, 2009: 9) yer alan "eş merkezli” ya da "ortak merkezli” daireler modeli, kültürel değere özel bir atıf geliştirmektedir.

2 Ankara Kültür Araştırması çalışmasında belirtildiği üzere (http://www.ccp. gov.tr, 2013: 13); "sembolik metin modeli"; kültürel sektörlerin toplumsal kültür üzerinde sahip oldukları dikkate alarak geliştirilen sınıflandırmayı içermektedir.

3 Bu çalışma öncesinde, aynı araştırmacının henüz değerlendirme aşamasındaki diğer çalışması, "Küreselleşme, Neo Liberalizm ve Yaratıcı Endüstriler: Alternatif Bir Yönetişim Üzerine Bir Not”, küresel yönetişim modeli içerisinde kültür ve yaratıcı endüstrileri tartışmayı amaçlamakta ve kültür ve yaratıcı endüstrilerin yönetişimi için ulusal bir politika önerisi geliştirmektedir.

1994 yılında Avustralya'nın “Creative Nations” projesi ile birlikte; kültür ve yaratıcı endüstriler yönetişimi kavramını ilk kullanan ülke Avustralya'dır (Rowe, Noble, Bennett ve Kelly 2016: 10).

Kavram; işletme yazını içerisinde önemli bir tartışma alanı olarak markaların küreselleşmesi içerisinde ele alınarak geliştirilmekte ve şirketlerin küreselleşmesi ve uluslararasılaşması eş anlamlı ve birbirinin yerine ikame edilerek kullanılmaktadır (Yeşil 2010: 37).

Nebi Özdemir (2009: 76), kültür ekonomisi ve endüstrilerinin yakın dönem içerisinde yaygın olarak, yaratıcı endüstriler biçiminde tanımlandığını belirtir. Özdemir'in vurguladığı üzere yaygın olan böylesi bir durum, kültürün yaratıcılık boyutunun öne çıkartılmasıyla ticari niteliğinin örtülmeye çalışıldığı biçiminde yorumlanmaktadır.

Yaratıcı ekonomiler bir dizi ölçüt çerçevesinde ele alınmaktadır. Bu doğrultuda, (1) yaratıcı değerlere dayanmak. (2) sosyal ve kültürel çeşitlilik ile insani gelişimi desteklerken, gelir oluşumu ve yeni iş alanları yaratılmasını ve ihracat kazançlarını belirlemek. (3) teknoloji, entelektüel nitelikler ve turizm hedefleriyle karşılıklı etkileşimli olmak. (4) Makro ve mikro ölçekte tüm ekonomiyle kesişen, bir dizi bilgi tabanlı ekonomik aktiviteden oluşmak. (5) Yenilikçi, çoklu, disiplinli ve bakanlıklar arası faaliyetler için uygulanabilirlik ve gelişim seçeneklerini oluşturmaktadırlar. Son olarak (6) Merkezlerinde, yaratıcı endüstrileri bulundururlar (aktaran Hocaoğlu, 2015:191).

8 James J. Gregory (2016: 160), yaratıcı endüstriler etrafında kurulan tar- 
tışmaların 2000'li yıllarla birlikte bu kez yaratıcı şehirler olmak üzere bir bütünleşmeye doğru bir evrim yaşadığını belirtir.

9 Des Freedman'ın (2006: 24-25) belirlediği üzere; ulus ötesi anlaşmaların mimarisi, tek başına Amerika Birleşik Devletleri’nin hegemonyasını pekiştirmeyi amaçlamaktadır

\section{Kaynaklar}

Artz, Lee (2015). Global Entertainment Media: A Critical Introduction. Malden, Oxford, West Sussex: Wiley Blackwell Publication.

Beukelaer, De Chrisrian (2017). "Toward an African take on the Cultural and Creative Industries". Media, Culture and Society 39(4): 582-591.

Beukelaer, De Christian (2014). "Creative Industries in "Developing" Countries: Questioning Country Classifications in the UNCTAD Creative Economy Reports". Cultural Trends 23(4): 232-251.

Department of Culture, Media and Sport (2001). "Creative Industries Mapping Document, 2001”. http://www.creativitycultureeducation.org (Erişim Tarihi: 22.01.2018).

Doyle, Gillian (2016). "Creative Industry and Policy". European Journal of Communication 31(1): 33-45.

Fahmi, Zikri Zul, Philip McCann ve Sierdjan Koster (2017). "Creative Economy Policy in Developing Countries: The Case of Indonesia”. Urban Studies 54(6): 1367-1384.

Flew, Terry (2012). The Creative Industries: Culture and Policy. London, California: Sage Publications.

Flew, Terry, Stuart Cunningham (2010). "Creative Industries After the First Decade of Debate”. The Information Society 26(2): 113-123.

Freedman, Des (2006). "Media Policy Making in the Free Trade Era: The Impact of the GATS Negotiations on Audiovisual Industries”. Trading Culture: Global Traffic and Local Cultures in Film and Television. içinde. Ed: Sylvia Harvey. Lincoln: John Bibley Publishing. 21-33.

Garnham, Nicholas (2006). "From Cultural to Creative Industries". International Journal of Cultural Policy. 15-29.

Gregory, James (2016). "Creative Industries and Urban Regeneration: The Maboneng Precint, Johannesburg”. Local Economy 31(1-2): 158-171.

Hartley, John, Jason Potts, Stuart Cunningham, Terry Flew, Michael Keane ve John Banks (2013). Key Concepts in Creative Industries. Washington Dc, Los Angeles, Londra, New Delhi ve Singapur: Sage Publications. 
Hocaoğlu, Dilek (2015). "Yaratıcı Endüstrilerin Yerel Ekonomilerdeki Önemi ve Tasarımın Bu Endüstrilere Katkısı". Planlama 25(3): 189-194.

http://www.bbc.com (2010). "Avrupa Kültür Başkentleri”. (Erişim Tarihi: 13.02.2018).

http://www.ccp.gov.tr (2013). "Ankara Kültür Ekonomisi: Sektörel Büyüklüklerin Değerlendirilmesi". (Erişim Tarihi: 04.02. 2018).

http://www.ec.europe.eu/culture (2012). "Communication from the Commission to the European Parliament. The Council, The European Economical Social Committee and the Committee of the Regions. Promoting Cultural and Creative Sectors for Growth and Jobs in the EU”. Brussels: COM 537". (Erişim Tarihi: 31.01.2018).

http://www.en.unesco.org (2017). "64 Cities Join the Unesco Creative Cities Network". (Erişim Tarihi: 13.02.2018).

http://www.en.unesco.org (2018). "Creative Cities Network". (Erişim Tarihi: 13.02.2018).

http://www.hdr.undp.org (2018). "Human Development Report”. (Erişim Tarihi: 08.02.2018).

http://www.internetworldstats.com (2018). "Internet Usage in Asia". (Erişim Tarihi: 13.02.2018).

http://www.internetworldstats.com (2018). "Internet Usage in Europe". (Erişim Tarihi: 13.02.2018).

http://www.keanet.eu (2009). "The Impact of Culture on Creavity: A Study Prepared for the European Commission Directore-General for Education and Culture”. (Erişim Tarihi: 25.11.2017).

http://www.keanet.eu (2009). "The Impact of Culture on Creavity: A Study Prepared for the European Commission Directore-General for Education and Culture". (Erişim Tarihi: 25.11.2017)

http://www.unctad.org (2008). "Creative Industry Report 2008: The Challenge of Assessing the Creative Economy. Towards Informed Policy-Making". (Erişim Tarihi: 31. 01. 2018).

http://www.unctad.org (2018). “About Unctad”. (Erişim Tarihi: 08.02.2018).

http://www.unctad.org. (2015). "Creative Industry Outlook and Country Profiles: Trends in International Trade in Creative Industries”. (Erişim Tarihi: 08.02.2018).

http://www.unctadstat.unctad.org. (2018). “Classifications”. (Erişim Tarihi: 08.02.2018).

http://www.unesco.org (2018). “Creative Industries”. (Erişim Tarihi: 31.01.2018). http://www.wipo.org (2018). "The Economic Performance of Copyright Based Industries”. (Erişim Tarihi: 31.01.2018). 
http://www.worldcreative.org (2017). "Cultural Times: The First Global Map of Cultural and Creative Industries". (Erişim Tarihi: 22.11.2017).

Jin, Dal Yong (2015). "New Perspectives on the Creative Industries in the Hallyu 2.0 Era: Global-Local Dialectics in Intellectual Properties". Hallyu 2.0: The Korean Wave in the Age of Social Media. Ed: Sangjoon Lee ve Abe Mark Nornes. Michigan: Michigan University Press. 53-73.

Lee, Sangjoon (2015). "From Diaspora TV to Social Media: Korean TV Dramas in America". Hallyu 2.0: The Korean Wave in the Age of Social Media içinde. Ed: Sangjoon Lee ve Mark Nornes. Michigan: Michigan University Press. 172-195.

McRobie, Angela (2016). Be Creative: Making a Living in the New Culture Industries. Malden: Polity Press.

Mitkus, Tomas (2016). "Internationalization Process of Creative Industries: Tendencies, Problems and Challenges". Forum Sciantiae Oeconomia 4(4): 27-37.

Özdemir, Nebi (2009). “Kültür Ekonomisi ve Endüstrileri ile Kültürel Miras Yönetimi İlişkisi”. Milli Folklor 84: 73-86.

Özdemir, Nebi (2012). Kültür Ekonomisi ve Yönetimi: Seçki. Ankara: Hacettepe Yayınları.

Rauning, Gerald (2013). "Kitlelerin Aldatılışı Olarak Yaratıcı Endüstriler”. Çev: Elçin Gen. http://www.skopdergi. Sayı: 4: 1-8. (Erişim Tarihi: 06.11.2017).

Rowe, David, Greg Noble, Tony Bennett ve Michelle Kelly (2016). "Transforming Cultures? From Creative Nation to Creative Australia”. Media International Australia 15(8): 6-16.

UNCTAD ve UNDP (2010). Creative Economy Report 2010: Creative Economy a Feasible Development Option. Geneva: United Nations Publications.

Yeşil, Salih (2010). "Küreselleşme ve İşletmelerin Küreselleşme Süreçleri: Karş1laşılan Fırsatlar ve Tehditler". Ekonomik ve Sosyal Araștırmalar Dergisi 6(6): 22-72. 


\title{
An Assessment on the Governance of the Creative Industries in the Turkish World ${ }^{*}$
}

\section{Serhat Kaymas*}

\begin{abstract}
This study is aimed to deal with cultural and creative industries, which is a notably remarkable for a new source of employment and welfare, within the developing countries perspectives. In this sense, the study has discussed these industries through the lens of contemporary conditions of the cultural and creative industries governance model and the study will focus on the following question: Is the cultural and creative industries whether the stand for sustainable development for the developing countries or these industries, especially at the dawn of the new century, is a new kind of cultural imperialism? The question is providing a bases for the study's research and in this sense the is seeking an entirely and meaningful answer for this debates. The study is based on public policy analysis and improvement of the some offers for the governance on the cultural and creative industries in the context of the Turkish World. As cultural and creative industries developing as a new source of employment and welfare for the countries in the globally, the governance model, and in this sense the debates on the developing of governmentality for these industries, has gain a privileged position. However well-structured discussion is ongoing in the literature on the governmentality of these industries, the developing countries has got only a few opportunities either "policy transfer" from developed countries and followed developed countries governmentality experiences or the new opportunities such as internationalization of their cultural and creative industries. Having evaluated cultural and creative industries governmentality models both developed and developing countries, at the end of the study the author of this article has offered some alternative government models for the Turkish World.
\end{abstract}

\section{Keywords}

Cultural industries, creative Industries, internet penetration and penetration rates, digital divides, knowledge society, governance of cultural and creative industries.

" Date of Arrival: 14 February 2018 - Date of Acceptance: 17 April 2018

You can refer to this article as follows:

Kaymas, Serhat (2019). “Türk Dünyasında Kültür ve Yaratıcı Endüstri Yönetişimi Üzerine Bir Değerlendirme”. bilig - Journal of Social Sciences of the Turkic World 90: 215-243.

${ }^{* *}$ Assoc. Prof. Dr., Hacettepe University, Faculty of Communication, Department of Communication Sciences - Ankara/Turkey

ORCID ID: https://orcid.org/0000-0003-4096-1546

ahmetserhat.kaymas@windowslive.com 


\title{
Оценка управления творческими индустриями в тюркском мире*
}

\section{Серхат Каймас ${ }^{* *}$}

\begin{abstract}
Аннотация
Данное исследование проводится с целью изучения культурных и творческих индустрий как новых источников процветания и занятости с точки зрения развивающихся стран. Культурные и творческие индустрии рассмотрены в контексте обсуждения моделей государственной политики и управления. В контексте реалий тюркского мира рассматривается вопрос о том, представляют ли рассматриваемые индустрии новое поле «возможностей» для развивающихся стран или новые формы империализма на заре XXI века. В работе сделан анализ государственной политики в этой сфере и выработаны рекомендации для тюркского мира. Что касается управления культурными и креативными индустриями в тюркском мире, то целью исследования было проверить модель интернационализации, примеры которой наблюдаются в опыте развитых стран. В работе обсуждаются модели управления культурными и креативными индустриями в тюркском мире и разработаны рекомендации, основанные на интернационализации культурных и творческих индустрий в тюркском мире.
\end{abstract}

\section{Ключевые слова}

Культурные индустрии, творческие индустрии, доступ в Интернет, цифровое разделение, общество знания, управление культурной и творческой индустриями.

\footnotetext{
* Поступило в редакцию: 14 февраля 2018 г. - Принято в номер: 17 апреля 2018 г. Ссылка на статью: Kaymas, Serhat (2019). “Türk Dünyasında Kültür ve Yaratıcı Endüstri Yönetişimi Üzerine Bir Değerlendirme”. bilig - Журнал Гуманитарных Наук Тюркского Мира 90: 215-243.

** Доц., д-р, университет Хаджеттепе, Факультет связи, кафедра коммуникационных наук Анкара / Турция ORCID ID: https://orcid.org/0000-0003-4096-1546 ahmetserhat.kaymas@windowslive.com
} 